\title{
Correlation between Entrepreneurial Orientation and Implementation of AI in Human Resource Management (HRM)
}

\author{
Rico Baldegger, Maurizio Caon, Kreshnik Sadiku
}

\author{
" Executives in companies around the world are increasingly looking to artificial \\ intelligence to create new sources of business value. This is especially true for \\ leading adopters of AI - those that have invested in AI initiatives and seen \\ impressive results. "
}

Sam Ransbotham, Philipp Gerbert, Martin Reeves, David Kiron, and Michael Spira, 2017

\begin{abstract}
This paper develops the concept of adopting artificial intelligence (AI) in human resource management (HRM) through a research questionnaire and reports the results of a study designed to investigate the perception of adopting and introducing AI in HRM processes. In addition, it investigates the correlation between entrepreneurial orientation (EO) and AI in HRM processes. A survey was conducted with a sample of 310 firm members in the HR Section Romande, as well as a literature review on the adoption of new technologies. The results indicate a perceived positive value of introducing AI in HRM and a correlation between the level of a company`s EO and the introduction of AI in HRM. This means that the more a company is entrepreneurially oriented, the more it tends to implement or include already implemented AI projects and tools in HRM processes.
\end{abstract}

The perceived value of AI in HRM was evaluated by comparing answers to research questions involving the introduction of AI in HRM tools, and expectations of widely implementing AI in the next five years. The main barrier of adopting AI in HRM appeared to be a lack of skills and training. In addition, potential features of implementing AI in HRM were identified as potential steps toward introducing AI as a new technology. Questions regarding the evaluation of EO were based on a research Colvin Slevin (1989).

It is important for SMEs to invest in information technology to set the basis for further development. Owing to intensified competitive pressures and the necessity of entering global markets, SMEs are incrementally employing Information Technology (IT) to create substantial benefits. Most prior research has focused more on IT adoption in large organizations, yet when regarding the limited resources of SMEs, the IT adoption process is considerably different. (Ghobakhloo, Sabouri, Hong and Zulkifli, 2011).

\section{Introduction and Background/Context}

The study directly assesses the link between entrepreneurial orientation (EO) and the introduction of artificial intelligence (AI) in human resources management (HRM). The paper aims at answering the research question: Is there any correlation between $E O$ \& the introduction of AI tools in HRM? EO is considered in three domains: innovation, proactiveness, and risk taking. Innovation is closely linked with the companies' internationalization.
Opportunities for competitive advantage arise by introducing new products or new services. The element of risk taking also plays an important role in internationalization for assessing expansion to unfamiliar markets. Creativity and innovativeness are an undisputable tool of digitalization that make a difference in a more competitive presence in the market. Improved processes data analysis are forcing companies to invest in advancing digitalization to prepare for an inevitable future with AI introduced in HRM. Moreover, digitalization advances are helping companies move 


\section{Correlation between Entrepreneurial Orientation and Implementation of AI in Human Resource Management (HRM) Rico Baldegger, Maurizio Caon, Kreshnik Sadiku}

ahead by providing personalized services.

Company executives around the world are increasingly looking to AI to create new sources of business value. This is especially true for leading adopters of AI, that have invested in AI initiatives and seen impressive results (Ransbotham et al., 2017). Improving business performance is the primary goal of most enterprises. Innovation in finding new tools and ways of creating better processes is an everyday challenge in today's economy. Improvement in business from humans has led to a new development of employing machines with AI in the workforce. Digitalization has made computers and machines a must for today's operations.

The first ideas about AI started in the 40s, when it was widely believed that machinery could function in an intelligent manner. $\mathrm{AI}$ is becoming the next buzz term in the plans of the largest corporations. By developing the right AI technology, a business can improve its market position by saving time and money. This happens by automating routine processes and tasks to make faster decisions based on outputs from cognitive technologies. AI has started to be integrated in several business processes with an aim to maximize the efficiency of processes.

HRM constitutes an important segment of any company. The introduction of AI in HRM will have an impact on both management practices in recruitment and HR management in general. In this paper, we consider the gap between the promises and reality of AI in HRM and suggest how progress might be made. We identify four challenges in using data science techniques in HR practices: 1) th complexity of HR phenomena, 2) constraints imposed by small data sets, 3) ethical questions associated with fairness and legal constraints, and 4) employee reaction to management via databased algorithms (Cappelli et al., 2019).

The term "artificial intelligence" takes on new attributes every day. The term was first used in 1956 by John McCarthy, to denote "The science and engineering of making intelligent machines" (in Peart, 2019). Today's definition identifies the theory and development of computer systems able to perform tasks normally requiring human intelligence, such as visual perception, speech recognition, decision-making, and translation between languages (Oxford Dictionaries of English, 2019). HR technology can be defined as any technology that is used to attract, hire, retain, and maintain human resources, support HR administration, and optimize HRM. HR technology is increasingly being used by small, medium, and large employers to meet the needs of its stakeholders (Bulmash, 2008).

The classical theoretical debates have centered on issues of whether AI is possible at all (often put as "Can machines think?"), or whether it can solve certain problems ("Can a machine do x?"). In the meantime, technical AI systems have progressed considerably and are now present in many aspects of our environment. Despite this development, there is a sense that classical AI is inherently limited, and must be replaced by (or supplanted with) other methods, especially neural networks, embodied cognitive science, statistical methods, universal algorithms, behavioral robotics, interactive systems, dynamic systems, along with insights from biology and neuroscience, evolutionary biology, and hybrid neuro-computational systems (Müller, 2012).

\section{Methodology}

\section{Focus and selection}

The author team conducted the survey between June and July 2019 with members of the Association of HR Section Romandes. It was distributed by the Association to company HR departments. In total, 541 members responded and 310 were taken into consideration after being reviewed for eligibility. In total, the survey had 72 questions. Extensive research on the available literature and data on the subject was conducted. Data in AI and organizational behavior were collected, based on the supposition that AI in HRM intersects with organizational behavior.

\section{Questionnaire}

This survey research represents the main data collected for the study. With approximately 3,000 members in the HR Section Romandes, the sample size is 310 for a margin error of $5 \%$, according to the platform surveymonkey for a population of 3,000 .

The survey questions were designed with the 5-item Likert Scale option. The survey was developed based on a theoretical framework made by the authors, and similar to other surveys from research studies. The survey was organized in seven sections: HR process, analysis of impact, fears and opportunities, AI features, focus on recruitment, data management, entrepreneurial orientation, and demographic data. 


\section{Correlation between Entrepreneurial Orientation and Implementation of AI in Human Resource Management (HRM) Rico Baldegger, Maurizio Caon, Kreshnik Sadiku}

The survey results were analyzed using two statistical tools:

- Descriptive statistics analysis to evaluate and understand the general situation, plans, and expectations from AI in HRM

- Hypothesis testing tools (t-tests, Chi Square, and ANOVA) to find statistical relationships between variables, such as EO, readiness, and adaption of $\mathrm{AI}$, including the perceived importance and fears regarding the impact of the AI, currently and in the future, in relation to easing the work of HRM, as well as fear of job losses.

\section{Results}

\section{Application areas}

The following results were found regarding the predicted impact that AI will have on business. Researchers predict that AI will outperform humans in many activities in the next ten years, such as translating languages (by 2024), writing high-school essays (by 2026), driving a truck (by 2027), working in retail (by 2031), writing a bestselling book (by 2049), and working as a surgeon (by 2053). Moreover, researchers believe there is a $50 \%$ chance of AI will advance to High Level Machine Intelligence (HLMI) in computing hardware, task performance, and automation of labor within 45 years, and will automate all human jobs within 120 years. (Grace et al., 2018). The rapid introduction of AI around the world suggests it is on the fast track to becoming an integrated part of our daily activities. Executives from the largest corporations in the USA ranked $\mathrm{AI}$ and machine learning as the most disruptive forces in the business landscape of the near future (New Vantage Partners, 2017). As well, a recent survey by Accenture (2017) revealed that $85 \%$ of executives have plans to invest extensively in AI-related technologies over the next 3 years (Jarrahi, 2018).

\section{AI applications in HRM}

Employing AI in HRM means delegating work from human beings to an external actor. The effect of delegation and of complementary adoption of AI, and in general of using AI to achieve pro-social interaction, is aimed at augmenting and multiplying the power of individual users to achieve their goals by exploiting the powers of other agents (Castelfranchi, 1998). The introduction and adoption of $\mathrm{AI}$ in the HRM process is a strong factor in determining perceptions about the future of AI and its potential of being adopted into HRM processes in the next five years.

Our survey results indicate that $47 \%$ of respondents "partly agree" with the statement that AI will be widely used in HRM processes in the next five years. At the same time, to the survey evaluated and assessed the percentage of those that have already introduced AI into their HRM processes. $31 \%$ answered Yes. In the crossanalysis of the data, we can see a significant difference between these two statements. This leads us to conclude when companies answered Yes to having already introduced and adopted AI into their HRM processes, the more they agreed that AI will be widely used in HRM processes in the next five years. For instance, HR cloud solutions that integrate conversational AI capabilities demonstrated how cognitive engines can help employees arrive at key day to-day decisions in the workplace. Historically, HR team members, employees, or managers would have had to handle these tasks. Instead, the application of these AIbased solutions allowed HRM processes to be reorganized in order to lighten the employees' workload (McGovern et al., 2018).

\section{Hypotheses}

The study tested the following hypotheses:

H10: There is no positive perceived value of AI usage in $H R M$, and

H11: There is a positive perceived value of AI usage in HRM.

H2o: There is no correlation between EO and the introduction of AI tools in HRM, and

H21: There is a correlation between EO and the introduction of AI tools in HRM.

In the first group, company innovativeness was tested, based on a descriptive statistical analysis and with hypothesis testing tools (chi-square, Phi and Cramer's V) that were used to prove statistical relationships between variables, such as EO readiness and adaption of AI. The chi-square results showed likelihood ratio results of 0.034 . Based on this result, we rejected H10. In evaluating the variables' relation with the Phi and Cramer's V analysis, results showed a moderate relation of 0.294 . 


\section{Correlation between Entrepreneurial Orientation and Implementation of AI in Human Resource Management (HRM) Rico Baldegger, Maurizio Caon, Kreshnik Sadiku}

The results of the chi-square analysis evidenced the same result in analyzing the second element of proactiveness, which resulted in our rejecting $\mathrm{H} 20$ and accepting H21. The Likelihood ratio was 0.001 and the analysis of the Phi and Cramer's V showed a strong relation of the variables 0.377 .

The likelihood ratio for the element of risk taking was 0.001, resulting in rejecting H20. The phi and Cramer's $\mathrm{V}$ also showed a strong relation between variables with a value of 0.374 .

\section{Discussions}

This study shows a correlation between the adoption of AI in HRM with their EO is statistically significant. This correlation suggests that the adoption of an emerging technology indeed constitutes a sign that a company is willing to take risks and is open to innovation. These factors are indeed both encompassed in the measurement of EO.

The EO of an organization denotes its processes, actions, methods, policies, practices, and decisionmaking styles within an organization (Mintzberg et al., 1976; Lumpkin \& Dess, 1996). As such, EO shows companies that have built a basis for entrepreneurial decision-making and taking action (Lumpkin \& Dess, 1996; Wiklund \& Shepherd, 2003).

Being grounded in strategy as well as entrepreneurship literature (Mintzberg et al., 1976; Miller \& Friesen, 1978, 1983; Venkatraman, 1989; Covin \& Slevin, 1991), EO comprises a multitude of concepts from several academic fields. Using Miller and Friesen's (1983) classification of firms as a starting point, three dimensions of EO have been frequently identified and applied in research: innovativeness, proactiveness and risk taking (Morris \& Paul, 1987; Miles \& Arnold, 1991; Smart \& Conant, 1994). This study's features involving EO in comparison with the introduction of AI in human resources, were thus assembled into three groups, according to this typology.

\section{Internationalization}

Risk taking consists of the tendency of a company to undertake risky actions, such as entering unfamiliar markets or taking on financial risk exposure actions to better perform as a way of getting ahead in the market. Thus, the impact of EO on the introduction of new technologies was first identified in the 1982 article
"Innovation in conservative and entrepreneurial firms" by Miller and Friesen. There they introduced a distinction between two types of strategic behavior: some firms are entrepreneurial, while others are more conservative. These two models of strategic momentum establish a distinction between two types of firms that lead them to insist on pursuing a given orientation. As a result, two types of innovation strategies can be identified, according to whether they are performed in response to environmental constraints (conservative strategies), or whether they proceed from top management convictions that value innovation as such, independently of the external context (entrepreneurial strategies) (Basso et al., 2009).

Empirical evidence has been found that the abovementioned measures of EO are associated with firms that perform better both in domestic and international markets (Knight, 1997; McDougall \& Oviatt 2000; Dimitratos \& Plakoyiannaki 2003; Kuivalainen et al., 2007; Robson et al., 2012; Wiklund \& Shepherd, 2005). Each new market entry is an entrepreneurial act that involves risk taking, innovation, and proactive behavior (Ellis, 2011). This is especially true for small firms.

The null hypothesis is therefore rejected that there is no correlation between companies that are risk taking and the introduction of AI in HRM. Thus, the results from companies that engage in risk taking also showed that these companies are keen not only to enter new markets, but also to adopt new technologies. Of particular note in companies we sampled is the fact that they perceive the use of AI in HRM positively and that a considerable number are already adopting AI tools.

We analyzed the survey's results for the question, "In general, the senior managers of my company have..." from option 1 - a high propensity for low risk projects (with normal and some rates of return) to option 5 - a high propensity for high-risk projects (with very high returns). As well, we addressed the question, "Has your HR team already implemented / is it already on the way to implementing AI-focused tools / solutions?" The results showed a likelihood ratio of 0.009 , which we interpret to mean that the result is not by chance, suggesting a correlation between the two features.

\section{Digitalization}

The first dimension of EO represents the innovativeness tendency of a company to introduce new products or 


\section{Correlation between Entrepreneurial Orientation and Implementation of AI in Human Resource Management (HRM) Rico Baldegger, Maurizio Caon, Kreshnik Sadiku}

services by means of creativity and experimentation, indicating its preference for attempting technological advances through research and development. The second dimension of $\mathrm{EO}$, proactiveness, reveals the approach a company takes toward opportunity seeking. This is translated into a tendency to develop and introduce new products or services ahead of competition. All of the dimensions of EO describe companies that seize opportunities for gaining competitive advantage.

Innovativeness impacts the overall performance of a company. An orientation towards innovativeness can have a positive effect on business performance as it translates into developing competitive advantage (Hurley \& Hult, 1998; Hult et al., 2004). Companies interested in innovation will focus on activities that improve their capacity to do so (Hurley \& Hult, 1998).
This capacity drives firms to improve continuously and, thus, tends to result in improved business performance.

The growing availability of data analysis nowadays is forcing companies to advance their technologies. Such advancement depends directly on digitalization, as the introduction of AI in HRM is closely linked with a company's EO level.

\section{Limitations and Future Research Directions}

The study was limited by a survey that had 72 questions. Approximately $42 \%$ of the responders did not complete the survey. In addition, the survey did not cover the profitability aspect of introducing AI in HRM. A further limitation in assessing the perception of $\mathrm{AI}$ is that it is largely a subjective matter. The surveyed persons' answers therefore might not reflect the perceptions of

Table 1. Demographics and company information of survey participants.

\begin{tabular}{|c|c|c|c|c|c|}
\hline \multicolumn{6}{|c|}{ Size of company (full-time equivalence) } \\
\hline $\begin{array}{l}1 \text { to } 10 \\
\text { employees }\end{array}$ & $\begin{array}{c}11 \text { to } 50 \\
\text { employees }\end{array}$ & $\begin{array}{l}51 \text { to } 250 \\
\text { employees }\end{array}$ & \multicolumn{3}{|c|}{$\begin{array}{c}\text { More than } \\
250 \text { employees }\end{array}$} \\
\hline $11 \%$ & $12 \%$ & $22 \%$ & \multicolumn{3}{|l|}{$55 \%$} \\
\hline \multicolumn{6}{|l|}{ Activity area } \\
\hline Public service & Industry & Health & Human Resources & Education & Other \\
\hline $16 \%$ & $11 \%$ & $9 \%$ & $7 \%$ & $7 \%$ & $50 \%$ \\
\hline \multicolumn{6}{|c|}{ HR workforce versus total manpower managed } \\
\hline Up to $1 \%$ & $1 \%$ to $2 \%$ & $2 \%$ to $5 \%$ & $+5 \%$ & & \\
\hline $30 \%$ & $42 \%$ & $19 \%$ & $8 \%$ & & \\
\hline \multicolumn{6}{|c|}{ Radius of action of company } \\
\hline Local & National & International & & & \\
\hline $40 \%$ & $31 \%$ & $29 \%$ & & & \\
\hline \multicolumn{6}{|c|}{ Age range of respondent } \\
\hline under 30 years & 31 to 50 years & \multicolumn{2}{|c|}{51 and plus } & & \\
\hline $3 \%$ & $61 \%$ & \multicolumn{2}{|c|}{$36 \%$} & & \\
\hline \multicolumn{6}{|l|}{ Education level } \\
\hline Learning & License & Bachelor & Master & Doctorate & Other \\
\hline $8 \%$ & $32 \%$ & $11 \%$ & $48 \%$ & $2 \%$ & $4 \%$ \\
\hline \multicolumn{6}{|l|}{ Field of study } \\
\hline Psychology & Law & Economy & Human resources & \multicolumn{2}{|c|}{ Other } \\
\hline $7 \%$ & $4 \%$ & $23 \%$ & $56 \%$ & \multicolumn{2}{|l|}{$10 \%$} \\
\hline \multicolumn{6}{|l|}{ Region } \\
\hline Fribourg & Geneva & Neuchatel & Valais & Vaud & Other \\
\hline $9 \%$ & $23 \%$ & $9 \%$ & $11 \%$ & $42 \%$ & $6 \%$ \\
\hline
\end{tabular}




\section{Correlation between Entrepreneurial Orientation and Implementation of AI in Human Resource Management (HRM) Rico Baldegger, Maurizio Caon, Kreshnik Sadiku}

the company's administration.

As the study does not cover the profitability aspect of introducing $\mathrm{AI}$ into HRM, this field should be the next direction to assessing whether or not introducing $\mathrm{AI}$ in HRM will bring profit for a company.

\section{Findings}

The demographics of the surveyed sample are as presented in Table \#1.

\section{Conclusions}

Global markets are volatile or uncertain at best. Talent turnover is a daily reality. Workweeks can be expected to regularly exceed 70 hours. As a result, management needs more efficiency and innovations to keep up. It has been suggested that AI has the potential to optimize processes across organizations (Oberholzer, 2019). While much uncertainty remains about what is to come with AI, nevertheless, every day the adoption and introduction of $\mathrm{AI}$ is becoming a necessity for business survival. The human resources sector is expecting changes and enhancements due to AI.

This study tested hypotheses regarding perceptions of AI in HRM through members of the HR Section Romandes. Through survey research that assessed the perceived value of AI in HRM, including its risks, constraints, and plans for its introduction, we found a general positive perception towards adopting $\mathrm{AI}$ in HRM. The survey results showed that the majority $(71 \%)$ of those surveyed believed that there will be both disappearance of jobs and creation of employment (= same number of jobs), while $23 \%$ believed that some jobs will disappear, and $6 \%$ believed that there will be new employments created (= more jobs). Thus, the fear of a negative impact in number of job losses is low. Regarding questions about assessing the perceived value of introducing $\mathrm{AI}$, the following statements give the attendant result. To the statement, "It is important for your business to have AI in HRM", from the survey, $17 \%$ strongly agreed, $47 \%$ partly agreed, $19 \%$ answered neutral, and $17 \%$ partly disagreed. To the statement, "AI becomes an indispensable tool for surviving market trends", $16 \%$ of the surveyed strongly agreed, $45 \%$ partly agreed, $26 \%$ answered neutral, $11 \%$ partly disagreed, and $2 \%$ strongly disagreed. The statement, "The use of the AI is an opportunity for the company" led to the following result: $29 \%$ strongly agreed, $48 \%$ partly agreed, $18 \%$ answered neutral, $4 \%$ partly disagreed, and $1 \%$ strongly disagreed. To the statement, "Companies that implement AI will have a competitive advantage in the market", $14 \%$ strongly agreed, $46 \%$ partly agreed, $30 \%$ were neutral, $10 \%$ partly disagreed, and $1 \%$ strongly disagreed. The majority of those surveyed agreed with the above statements and perceived the impact of AI on HRM processes positively.

As a result of our findings, we believe that AI technology should be carefully evaluated and introduced, and that enterprises must ensure proper system information and knowledge transfer to HR employees to avoid fear of job losses and confusion. However, introducing AI depends heavily on the EO of a company. Therefore, we recommend evaluating the EO of companies considering the introduction of $\mathrm{AI}$ in HRM according to three dimensions: innovativeness, proactiveness, and risk taking.

The study supported the rejection of $\mathrm{H} 0$, that there is no positive perceived value of introducing AI in HRM. The study also supported the rejection of $\mathrm{H} 20$, that there is no correlation between $\mathrm{EO}$ and the introduction of AI tools in HRM. The result was statistically significant, showing a clear correlation between EO and the introduction of AI tools in HRM. A key priority is to ensure that the benefits of an AI system can enhance and improve HRM processes rather than harming them. Finally, the topic of AI in HRM is on the cutting-edge and thus some people are skeptical of its adoption. It is therefore now time to start preparing for what seems likely soon to come with its adoption in HR practices. Long-term planning is needed to ensure a place for AI projects. Data management drives this opportunity door for HRM, wherein companies that build a sustainable and efficient data management system today can look forward to a brighter future with AI tomorrow. 


\section{Correlation between Entrepreneurial Orientation and Implementation of AI in Human Resource Management (HRM) Rico Baldegger, Maurizio Caon, Kreshnik Sadiku}

\section{References}

Accenture. 2017. Technology vision 2017: Technology for people. Dublin, Ireland: Accenture.

Basso, O., Fayolle, A., and Bouchard, V. 2009. Entrepreneurial Orientation: The Making of a Concept. The International Journal of Entrepreneurship and Innovation, 10(4): 313-321. https://doi.org/10.5367/000000009790012327

Bouwman, H., Nikou, S., and de Reuver, M. 2019. Digitalization, business models, and SMEs: How do business model innovation practices improve performance of digitalizing SMEs? Telecommunications Policy, 43(9), 101828.

Bulmash, J. 2008. Human Resources Management and Technology. Retrieved from:

https://catalogue.pearsoned.ca/assets/hip/us/hip_u s_pearsonhighered/samplechapter/ 0132270870pdf [Äccessed 17 March 2020]

Cappelli, P., Tambe, P., and Yakubovich, V. 2019. Artificial intelligence in human resources management: challenges and a path forward. Available at SSRN 3263878.

Castelfranchi, C. 1998. Modelling social action for AI agents. Artificial intelligence, 103(1-2): 157-182.

Covin, J. G., and Slevin, D. P. 1991. A conceptual model of entrepreneurship as firm behavior. Entrepreneurship Theory and Practice, Fall: 7-25.

Dimitratos, P., and E. Plakoyiannaki, E. 2003. "Theoretical Foundations of an International Entrepreneurial Culture. Journal of International Entrepreneurship, 1(2): 187-215.

Ellis, P. (2011). Social Ties and International Entrepreneurship: Opportunities and Constraints Affecting Firm Internationalization. Journal of International Business Studies, 42(1): 99-127.

Grace, K., Salvatier, J., Dafoe, A., Zhang, B., and Evans, O. 2018. When will AI exceed human performance? Evidence from AI experts. Journal of Artificial Intelligence Research, 62: 729-754.

Ghobakhloo, M., Sabouri, M.S., Hong, T.S., \& Zulkifli, N. 2011. Information technology adoption in small and medium-sized enterprises; an appraisal of two decades literature. Interdisciplinary Journal of Research in Business, 1(7): 53-80.

Hult, G.T.M., Hurley, R.F., \& Knight, G.A. 2004. Innovativeness: Its antecedents and impact on business performance. Industrial Marketing Management, 33(5): 429-438.

Hurley, R.F., and Hult, G.T.M. 1998. Innovation, market orientation, and organizational learning: An integration and empirical examination. Journal of Marketing, 62(3): 42-54.
Jarrahi, M.H. 2018. Artificial intelligence and the future of work: Human-AI symbiosis in organizational decision making. Business Horizons, 61(4): 577-586.

Knight, G.A. 1997. Cross-cultural reliability and validity of a scale to measure firm entrepreneurial orientation. Journal of Business Venturing, 12(3): 213225.

Kuivalainen, O., Sundqvist, S., \& Servais, P. 2007. Firms' degree of born-globalness, international entrepreneurial orientation and export performance. Journal of World Business, 42(3): 253-267.

Lumpkin, G.T., and Dess, G.G. 1996. Clarifying the entrepreneurial orientation construct and linking it to performance. Academy of Management Review, 21(1): 135-172.

McDougall, P.P., and B.M. Oviatt (2000). “International Entrepreneurship: The Intersection of Two Research Paths." Academy of Management Journal 43(5): 902906.

McGovern, S., Pandey, V., Gill, S., Aldrich, T., Myers, C., Desai, C., Gera, M. and Balasubramanian, V. (2018). The new age: artificial intelligence for human resource opportunities and functions. Ey.com. Available

https://www.ey.com/Publication/vwLUAssets/EYthe-new-age-artificial-intelligence-for-humanresource-opportunities-and-functions/\$FILE/EYthe-new-age-artificial-intelligence-for-humanresource-opportunities-and-functions.pdf [Accessed 17 April 2020]

Miles, M.P., and Arnold, D.R. 1991) The relationship between marketing orientation and entrepreneurial orientation. Entrepreneurship Theory and Practice, 15: 49-65.

Miller, D., \& Friesen, P.H. 1978. Archetypes of strategy formulation. Management Science, 24(9), 921-933.

Miller, D., and Friesen, P. H. 1983. The correlates of entrepreneurship in three types of firms. Management Science, 29(7): 770-791.

Miller, D., and Friesen, P. H 1982. "Innovation in Conservative and Entrepreneurial Firms: Two Models of Strategic Momentum." Strategic Management Journal, vol. 3, no. 1, 1982, pp. 1-25.

Mintzberg, H., Raisinghani, D., and Théorêt, A. 1976. The Structure of "Unstructured" Decision Processes. Administrative Science Quarterly, 21(2): 246-275.

Morris, M. H., \& Paul, G. W. 1987. The relationship between entrepreneurship and marketing in established firms. Journal of Business Venturing, 2(3): 247-259.

Müller, V. C. 2012. Autonomous cognitive systems in real-world environments: Less control, more flexibility and better interaction. Cognitive Computation, 4(3): 212-215. 


\section{Correlation between Entrepreneurial Orientation and Implementation of AI in Human Resource Management (HRM) Rico Baldegger, Maurizio Caon, Kreshnik Sadiku}

New Vantage Partners. 2017. Big data executive survey 2017. Retrieved from:

http://newvantage.com/wp-content/ uploads/2017/01/Big-Data-Executive-Survey-2017Executive-Summary.pdf [Accessed 17 March 2020]

Oberholzer, E. 2019. Artificial intelligence -Switzerland lags behind global competitors. Pwc.ch. Retrieved from: releases/pwc-mr-

https://www.pwc.ch/de/press-room/pressswitzerland_artificial\%20intelligence-2019-en.pdf [Accessed $1 \overline{7}$ March 2020]

Peart, A. 2019. Homage to John McCarthy, the Father of Artificial Intelligence (AI). Conversational AI Platform: Artificial Solutions. Retrieved from: https://www.artificial-solutions.com/blog/homageto-john-mccarthy-the-father-of-artificial-intelligence [Accessed 17 March 2020]

Ransbotham, S., Gerbert, P., Reeves, M., Kiron, D., and Spira, M. 2018. Artificial intelligence in business gets real. MIT Sloan Management Review, 60280.

Robson, P. J. A., Akuetteh, C.K., Westhead, P. and Wright. M. 2012. "Exporting Intensity, Human Capital and Business Ownership Experience." International Small Business Journal 30(4): 367-387.

Smart, D. T., and Conant, J. S. 1994. Entrepreneurial orientation, distinctive marketing competencies and organizational performance. Journat of Applied Business Research, 10: 28-38.

Venkatraman, N. 1989. Strategic orientation of business enterprises: The construct, dimensionality, and measurement. Management Science, 35(8): 942-962.

Wiklund, J., and Shepherd, D. 2003. Knowledge-based resources, entrepreneurial orientation, and the performance of small and medium-sized businesses. Strategic Management Journal, 24(13): 1307-1314.

Wiklund, J., and Shepherd, D. 2005. "Entrepreneurial Orientation and Small Business Performance: A Configurational Approach." Journal of Business Venturing, 20(1): 70-91.

\section{About the Authors}

Prof. Rico Baldegger is Director and Professor of Strategy, Innovation and Entrepreneurship at the School of Management Fribourg (HEG-FR), Switzerland. He has studied at the Universities of St. Gallen and Fribourg, Switzerland. His research activities concentrate on innovative start-ups, the entrepreneurial behavior of individuals and organizations, as well as the phenomenon of rapidgrowth companies. He has published several books and articles and, since the beginning of the 1990s, he has been the manager of a business for company development. Moreover, he is a business angel and serial entrepreneur, as is demonstrated by the many companies he has created.

Maurizio Caon is currently Associate Professor and Leader of the Digital Business Center at the School of Management Fribourg, member of the University of Applied Sciences and Arts Western Switzerland (HESSO). $\mathrm{He}$ is also lecturer at the College of Engineering Fribourg, director of design and innovation at the HumanTech Institute and member of Centre Compétences Numériques (also part of HES-SO). He holds a Ph.D. in Computer Science issued by the University of Bedfordshire, UK, and a Master's degree in Telecommunications and Computer Engineering issued by the University of Perugia, Italy. His research interests include human-computer interaction, human factors in digital technologies and digital transformation.

Kreshnik Sadiku graduated in the MSc in Business Administration major Entrepreneurship in HES-SO. He published a book "Path toward Entrepreneurship" on 2012 and works currently as Regional Manager in a company that provides financial services.

\footnotetext{
Citation: Baldegger, R.,Caon, M., Sadiku, K. 2020.

Correlation between Entrepreneurial Orientation and

Implementation of AI in Human Resource Management

(HRM). Technology Innovation Management Review, 10(4):

72-79.

http://doi.org/10.22215/timreview/1348
}

(cc) BY 